\title{
Carbon nanodots interference with lactate dehydrogenase assay in human monocyte THP-1 cells
}

Petra C Wright ${ }^{1}$, Hu Qin ${ }^{2}$, Martin MF Choi ${ }^{2}$, Norman HL Chiu ${ }^{1,3^{*} \dagger}$ and Zhenquan Jia ${ }^{4^{*}+}$

\begin{abstract}
Background: Carbon nanodots (CD), a new class of carbon nanomaterials with sizes below $10 \mathrm{~nm}$, have recently attracted wide attention due to their superiority in water solubility, chemical inertness, and resistance to photobleaching. As a result, CD has found important and wide applications in energy, catalysis, biological labeling, bioimaging and drug delivery. On the other hand, due to the lack of available toxicity data, there is a growing concern regarding the potential risks of $C D$. Hence, accurate assessment of the cytotoxicity of $C D$ has become more important than ever before. The lactate dehydrogenase $(\mathrm{LDH})$ assay is widely used to detect cytotoxicity of various nanoparticles including CD. Many recent studies used LDH assay to study the CD toxicity in various cells. However, these studies failed to further examine whether the CD were interfering with the LDH assay which would alter their findings.

Findings: This study investigated the possible interference of carbon nanodots on the LDH assay in human monocyte THP-1 cells. Monocytes are known to be involved in inflammable vascular diseases, and have been suggested to be the targets for $C D$ exposure. In this study, the cytotoxicity of $C D$ in concentrations ranging from 0.075 to $0.60 \mathrm{mg} / \mathrm{mL}$, was determined by using the LDH assay. To validate the results of LDH assay, the cell counting method with trypan blue staining was used. With 24 hours incubation time, the cell viability of THP-1 was significantly decreased according to the trypan blue staining method. Whereas, in the LDH assay, the CD was found to interfere in a dose-dependent manner with the NADH absorbance measurements at $340 \mathrm{~nm}$.
\end{abstract}

Conclusions: This study represents the first report on the negative interference of CD on LDH assay, and caution should be observed when evaluating the cytotoxicity of CD.

Keywords: Carbon nanodots; Interference; Lactate dehydrogenase assay; Trypan blue staining; Cytotoxicity

\section{Introduction}

Carbon nanomaterial production has increased globally in the past few years and risk assessment for carbon nanomaterials is not completely established (Tsuji et al. 2006). Their physical and chemical properties allow them to be great candidates for imaging, photocatalysis, cancer cell inhibition, and disease diagnosis (Hsu et al. 2013; Juzenas et al. 2013; Tang et al. 2013; Zhang et al. 2013). Carbon

\footnotetext{
* Correspondence: prof.chiu@gmail.com; z_jia@uncg.edu

${ }^{\dagger}$ Equal contributors

'Department of Chemistry and Biochemistry, University of North Carolina at Greensboro, Greensboro, NC 27412, USA

${ }^{4}$ Department of Biology, University of North Carolina at Greensboro,

Greensboro, NC 27412, USA

Full list of author information is available at the end of the article
}

nanodots $(C D)$, a new class of carbon nanomaterials with sizes below $10 \mathrm{~nm}$, have recently attracted wide attention due to their superiority in water solubility, chemical inertness, and resistance to photobleaching (Baker and Baker 2010; Hsu and Chang 2012; Shi et al. 2011; Zhou et al. 2012). As a result, CD has found important and wide applications in energy, catalysis, biological labeling, bioimaging and drug delivery (Baker and Baker 2010; Hsu and Chang 2012; Shi et al. 2011; Zhou et al. 2012). Although $\mathrm{CD}$ are considered to be biocompatible, there have been cases where $\mathrm{CD}$ is identified as toxic agent for various biological tissues (Hsu et al. 2013; Zhang et al. 2013). Therefore, it is important that the risk assessment is thoroughly examined before administering them for medical use. The correlation between exposure to nanoparticles and vascular

\section{实}


diseases is of particular concern (Mossman et al. 2007; Beck and Offenbacher 2001). Monocytes are known to play crucial role in the development of inflammable vascular diseases and have been suggested to be significant targets for nanoparticle exposure (Prach et al. 2013).

Although there are different types of assays that can be applied to evaluate the cytotoxicity of nanomaterials, lactate dehydrogenase (LDH) assay has been considered to be the gold standard for measuring cytotoxicity (Kroll et al. 2012). The LDH enzyme is shared amongst all cell types and is released upon damage to the cell membrane. The LDH assay has been used to access the properties of $\mathrm{CD}$, as a way to support $\mathrm{CD}$ induces apoptosis instead of necrosis (Hsu et al. 2013). Hsu et al., measured the integrity of the cell membranes of three different cancer cell lines MCF-7, MDA-MB-231, and HeLa by using the LDH assay. They found that after $24 \mathrm{~h}$ incubation with $\mathrm{CD}$ there wasn't any increase in the release of LDH in any of the selected cell lines (Hsu et al. 2013). However, they did not further examine whether the $C D$ were interfering with the LDH assay which would alter their findings. This study focuses on the investigation of possible interference of carbon nanodots on the LDH assay in human monocyte THP-1 cells.

\section{Methods}

\section{Synthesis and characterization of carbon nanodots}

Carbon nanodots were synthesized as reported recently by us (Hu et al. 2013). Briefly, $0.50 \mathrm{~g}$ citric acid (CA) was dissolved in $5.0 \mathrm{~mL}$ distilled deionized (DDI) water followed by mixing with various amounts of 1,2-ethylenediamine (EDA, 0.00-0.47 g) under vigorous stirring in glass vials. The solution was then heated in a domestic microwave oven $(800 \mathrm{~W})$ for $4.0 \mathrm{~min}$ and the glass vial was cooled down to room temperature. The reddish brown and foamy solid was then dissolved in DDI water and dialyzed through a dialysis membrane with MWCO of 500-1000 Da (Spectrum Laboratories, Rancho Dominguez, CA, USA) and a clear and reddish brown aqueous solution was lyophilized to obtain $c a .0 .050 \mathrm{~g}$ dry C-dots product. Various optical determinations including UV-vis absorption, photoluminescence spectroscopy, IR spectroscopy and mass spectrum were employed to characterize the as-synthesized C-dots as described by us recently (Hu et al. 2013).

\section{Cell culture and treatment}

The human monocyte THP-1 cells (ATCC, Manassas, VA) were maintained in RPMI-1640 medium supplemented with fetal bovine serum (10\%), penicillin-streptomycin (1\%) antibiotic in $5 \% \mathrm{CO}_{2}$ at $37^{\circ} \mathrm{C}$. All these chemicals and media were purchased from Sigma-Aldrich (St Louis, MO). Prior to confluence, the cells were collected and centrifuged for $10 \mathrm{~min}, 4^{\circ} \mathrm{C}, 1000 \mathrm{~g}$. The supernatant was decanted and the cell pellet was re-suspended in Dulbecco's Modified Eagle's medium (DMEM) The cells were then seeded in a 24 -well plate at a density of $4.0 \times 10^{5}$ cells per mL. CD (0.60 mg) were mixed with DMEM ( $1 \mathrm{~mL})$, an aliquot $(400 \mathrm{uL})$ of this mixture was added to each well, and was incubated for $24 \mathrm{~h}$.

\section{LDH assay}

The cytotoxic effects of $\mathrm{CD}$ were first measured by quantitating the release of lactate dehydrogenase (LDH) from the THP-1 cells. Following incubation, an aliquot (200 uL per well) of treated cells were centrifuged for $5 \mathrm{~min}, 4^{\circ} \mathrm{C}, 13,000 \times \mathrm{g}$. The untreated cells $(200 \mathrm{uL}$ per well) were sonicated then centrifuged. The supernatants were collected for LDH measurements. Reagents for $\mathrm{LDH}$ assay were $60 \mathrm{uL}$ per well of $0.8 \mathrm{mg} / \mathrm{mL}$ pyruvate, $60 \mathrm{uL}$ per well of $3 \mathrm{mg} / \mathrm{mL}$ NADH. A total assay volume of $600 \mathrm{uL}$ was made up with $1 \mathrm{X}$ phosphate buffered saline (PBS, pH 7.4). NADH was added last, and the cuvette was immediately placed in the spectrophotometer. In the spectrophotometer, the oxidation of NADH was monitored at $340 \mathrm{~nm}$ for over $5 \mathrm{~min}$.

\section{Trypan blue viability assay}

The cell number and cell viability were determined by using the cell counting method. Cells (100 uL per well) were mixed with trypan blue dye $(100 \mathrm{uL})$ and $20 \mathrm{uL}$ of this cell-dye mixture was loaded onto a hemacytometer. Each mixture was counted four times by using all four grids on the hemacytometer. When digital EVOS microscope was used, an aliquot of $10 \mathrm{uL}$ of the cell-dye mixture was added on a microscope slide.

\section{Measurement of CD absorbance with a spectrophotometer}

The CD $(0.15 \mathrm{mg})$ was dissolved in deionized water $(0.25 \mathrm{~mL})$ for absorbance measurements. Serial dilutions were performed for concentrations of $0.45,0.30,0.15$, $0.075 \mathrm{mg} / \mathrm{mL}$. Each $\mathrm{CD}$ dilution $(10 \mathrm{uL})$ was added to the $\mathrm{LDH}$ reagents $(60 \mathrm{uL} \mathrm{NADH}, 60 \mathrm{uL}$ pyruvate, and $490 \mathrm{uL}$ 1X PBS), and absorbance was read at $340 \mathrm{~nm}$.

\section{Statistical analyses}

Data were analyzed with one-way ANOVA and are expressed as mean \pm SEM based on quadruple and triplicate observations, respectively. After ANOVA, statistical significance between the treatment and control groups was determined by Student $\mathrm{t}$-test and defined at $\mathrm{p}<0.05$ level.

\section{Results and discussion}

Recent studies have demonstrated that exposure to nanoparticles could elevate the risk of vascular diseases. Monocytes are known to be involved in inflammable vascular diseases, and have been suggested to be the targets for nanoparticle exposure. In this study, the cytotoxicity of 


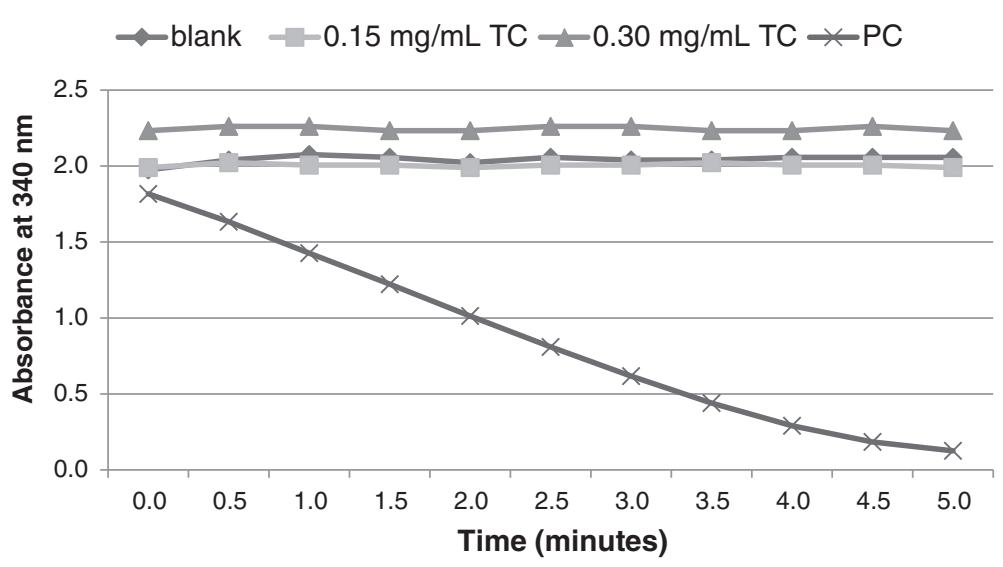

Figure 1 Results of LDH assays of THP-1 cells with or without CD. Cells were treated without or with $0.15 \mathrm{mg} / \mathrm{mL}$ and $0.30 \mathrm{mg} / \mathrm{mL} C D$ for $24 \mathrm{~h}$. Blank contained PBS buffer only. Supernatant from treated cells (TC) was measured by mixing 5 or $10 \mathrm{uL}$ of supernatant with $595 \mathrm{or} 590 \mathrm{uL}$ of $L D H$ reagents, respectively. Positive control (PC) consisted of lysate from control cells in the absence of CD.

monocytes, after exposure to $\mathrm{CD}$ in concentrations ranging from 0.075 to $0.60 \mathrm{mg} / \mathrm{mL}$, was determined by using the LDH assay. Figure 1 displays the LDH absorbance in the presence and absence of $\mathrm{CD}$. There was a pronounced effect of LDH release in the cell lysate (Figure 1, positive control) indicating LDH was utilizing NADH in its conversion to pyruvate. The decrease in NADH absorbance over time confirmed that the reagents and instrument were operating properly. However, after $24 \mathrm{~h}$ incubation with $0.15 \mathrm{mg} / \mathrm{mL}$ and $0.30 \mathrm{mg} / \mathrm{mL}$ of $\mathrm{CD}$, the $\mathrm{CD}$ did not cause any increase in the release of LDH from the THP-1 cells (Figure 1).

To validate the results of LDH assay, the cell counting method with trypan blue staining was used (Figure 2).
Incubation of cells with various concentrations of $\mathrm{CD}$ for 24 hours caused a significant decrease in cell viability measured by trypan blue staining (Figure 2). The cell morphology changes by $\mathrm{CD}$ were further examined with a digital microscope (Figure 3). In comparison to the control, the cells treated with CD display significant changes in cell morphology including a loss of uniformity and detritus surrounding the cell clusters as indicated by the arrows in Figure 3. The inconsistency results between Figure 1 (LDH assay) and Figures 2 and 3 (trypan blue staining and digital microscope) by $\mathrm{CD}$ treatments lead us to suspect $\mathrm{CD}$ could interfere with the NADH absorbance measurements in the LDH assay (Figure 1).

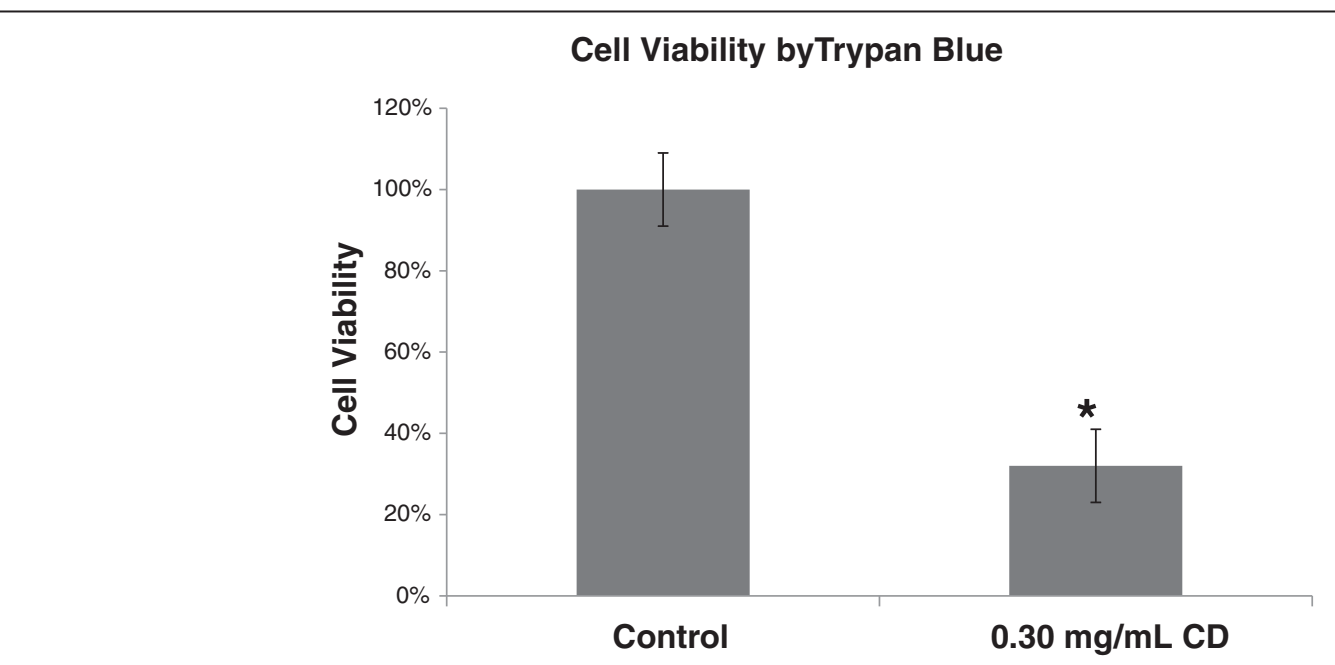

Figure 2 Cell viability of THP-1 cells determined by cell counting with Trypan blue staining method with or without CD. The percentage of viable cells was normalized to the negative control, which was calculated by multiplying the ratio of (number of living cells in treated sample: number of living cells in negative control) with 100\%. Data are expressed as mean \pm SEM from four experiments. ${ }^{*}, \mathrm{p}<0.05$ vs. control. 


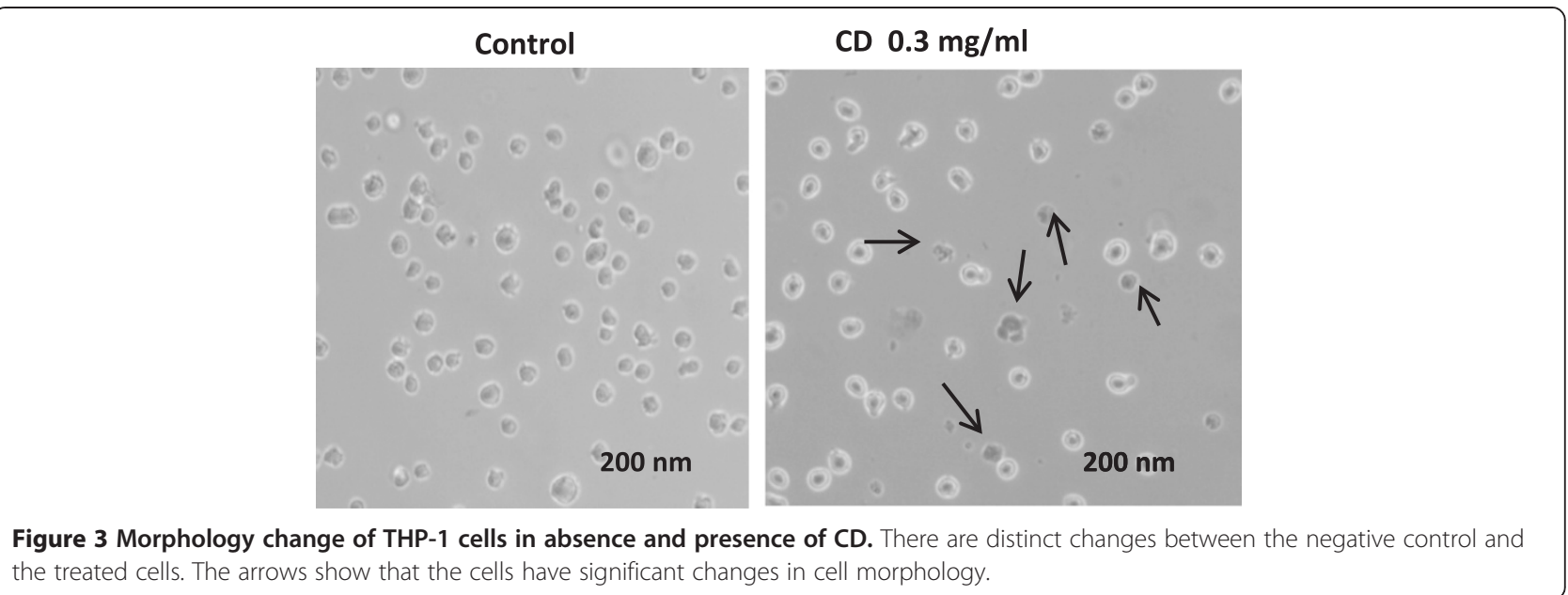

The absorbance of $\mathrm{CD}$ at $340 \mathrm{~nm}$ was measured to confirm its interference with the LDH assay (Figure 4). The absorbance of CD in the absence of THP-1 cells was measured in concentrations ranging from 0.075 to $0.60 \mathrm{mg} / \mathrm{mL}$. The absorbance of CD at $340 \mathrm{~nm}$ increased as the concentrations increased $\left(R^{2}=0.9883\right.$, Figure 4$)$. This trend was observed in the LDH assay, suggesting that there was interference on the NADH absorbance (340 $\mathrm{nm}$ ) by the CD.

Although the LDH assay is widely used to detect cytotoxicity of various nanoparticles including CD, there is limited information on the possible interference of LDH on carbon nanodots (CD). Recently, Hsu et.al reported that the observed cytotoxicity of carbon nanodots did not increase the release of $\mathrm{LDH}$ following $24 \mathrm{~h}$ incubation of MCF-7, MDA-MD-231 and HeLa cells with CD concentrations ranging from 0.075 to $0.60 \mathrm{mg} / \mathrm{mL}$ (Hsu et al. 2013). However, the authors failed to further examine whether CD was interfering with the LDH assay which might alter their conclusion. In this study, we are the first to report that CD was found to interfere with the NADH absorbance measurements in the LDH assay in a dose-dependent manner. Our results suggest that LDH assay should not be used to evaluate the cytotoxicity of CD that potentially leads to a false conclusion on the cytotoxicity of carbon nanodots as reported by Hsu et.al (Hsu et al. 2013). The traditional trypan blue staining method proved to be a viable approach for evaluating the cytotoxicity of nanomaterials, whose chemical and physical properties may not be known. This method has been used to access the cytotoxicity of multi-walled carbon nanotubes, however it is fairly time consuming. Therefore, an improved method is needed to determine the risk assessment of $\mathrm{CD}$ for any future development or application.

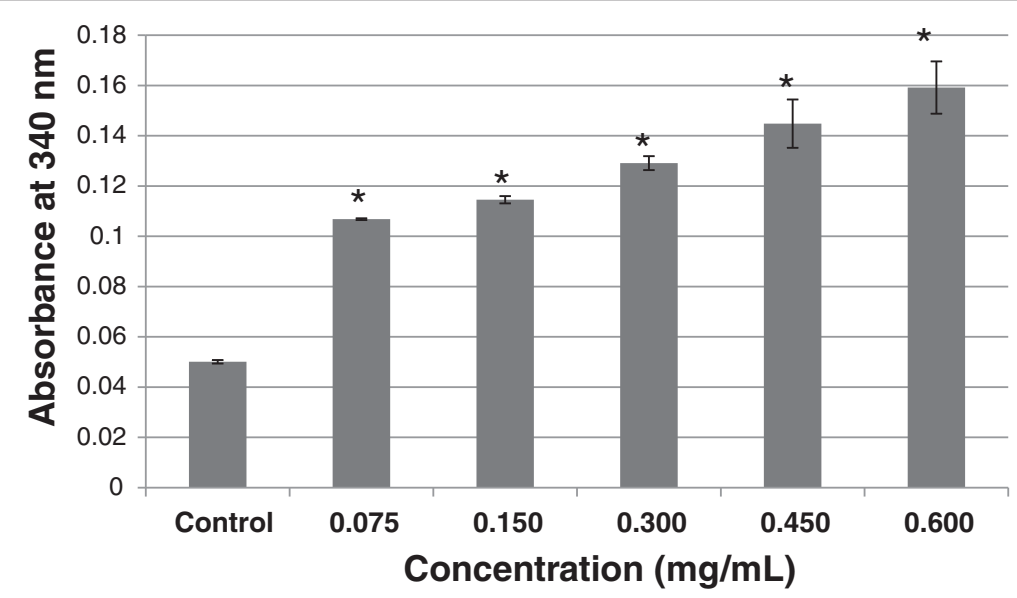

Figure 4 Absorbance of $C D$ at $\mathbf{3 4 0} \mathbf{n m}$. The reported values (mean \pm SD) were corrected by subtracting the background absorbance from PBS buffer. Data are expressed as mean \pm SEM from three experiments. ${ }^{*}, \mathrm{p}<0.05$ vs. control. 


\section{Abbreviations}

CA: Citric acid; CD: Carbon nanodots; DMEM: Dulbecco's Modified Eagle's medium, EDA, 1,2-ethylenediamine; LDH: The lactate dehydrogenase; PBS: Phosphate buffered saline; PC: Positive control.

\section{Competing interests}

The authors declare that they have no competing interests.

\section{Authors' contributions}

ZJ, NHLC and MMFC made contributions to the conception and design. PCW and HQ performed the experiments. All authors read and approved the final manuscript.

\section{Funding support}

This work was supported in part by National Institutes of Health (7R15AT005372-02) and a grant from UNCG.

\section{Author details}

${ }^{1}$ Department of Chemistry and Biochemistry, University of North Carolina at Greensboro, Greensboro, NC 27412, USA. ²Department of Chemistry, Hong Kong Baptist University, Kowloon Tong, Hong Kong, SAR, China. ${ }^{3}$ Department of Nanoscience, Joint School of Nanoscience and Nanoengineering, Greensboro, NC 27401, USA. ${ }^{4}$ Department of Biology, University of North Carolina at Greensboro, Greensboro, NC 27412, USA.

Received: 21 August 2014 Accepted: 10 October 2014

Published: 18 October 2014

\section{References}

Baker SN, Baker GA (2010) Luminescent carbon nanodots: emergent nanolights. Angew Chem Int Ed Engl 49(38):6726-6744, doi: 10.1002/anie.200906623

Beck JD, Offenbacher S (2001) The association between periodontal diseases and cardiovascular diseases: a state-of-the-science review. Ann Periodontol 6(1):9-15

Hsu PC, Chang HT (2012) Synthesis of high-quality carbon nanodots from hydrophilic compounds: role of functional groups. Chem Commun (Camb) 48(33):3984-3986, doi: 10.1039/c2cc30188a

Hsu P-C, Chen P-C, Ou C-M, Chang H-Y, Chang H-T (2013) Extremely high inhibition activity of photoluminescent carbon nanodots toward cancer cells. J Mater Chem B 1(13):1774-1781

Hu Q, Paau MC, Zhang Y, Chan W, Gong X, Zhang L, Choi MM (2013) Capillary electrophoretic study of amine/carboxylic acid-functionalized carbon nanodots. J Chromatogr A 1304:234-240, doi: 10.1016/j.chroma.2013.07.035

Juzenas P, Kleinauskas A, Luo PG, Sun Y-P (2013) Photoactivatable carbon nanodots for cancer therapy. Appl Phys Lett 103(6):063701

Kroll A, Pillukat MH, Hahn D, Schnekenburger J (2012) Interference of engineered nanoparticles with in vitro toxicity assays. Arch Toxicol 86(7):1123-1136

Mossman BT, Borm PJ, Castranova V, Costa DL, Donaldson K, Kleeberger SR (2007) Mechanisms of action of inhaled fibers, particles and nanoparticles in lung and cardiovascular diseases. Part Fibre Toxicol 4(4):8974-8977

Prach M, Stone V, Proudfoot L (2013) Zinc oxide nanoparticles and monocytes: impact of size, charge and solubility on activation status. Toxicol Appl Pharmacol 266(1):19-26

Shi W, Wang Q, Long Y, Cheng Z, Chen S, Zheng H, Huang Y (2011) Carbon nanodots as peroxidase mimetics and their applications to glucose detection. Chem Commun (Camb) 47(23):6695-6697, doi: 10.1039/ c1cc11943e

Tang J, Kong B, Wu H, Xu M, Wang Y, Wang Y, Zhao D, Zheng G (2013) Carbon nanodots featuring efficient FRET for real-time monitoring of drug delivery and two-photon imaging. Adv Mater 25(45):6569-6574

Tsuji JS, Maynard AD, Howard PC, James JT, C-w L, Warheit DB, Santamaria AB (2006) Research strategies for safety evaluation of nanomaterials, part IV: risk assessment of nanoparticles. Toxicol Sci 89(1):42-50
Zhang X, He X, Li Y, Zhang Z, Ma Y, Li F, Liu J (2013) A cytotoxicity study of fluorescent carbon nanodots using human bronchial epithelial cells. J Nanosci Nanotechnol 13(8):5254-5259

Zhou L, Lin Y, Huang Z, Ren J, Qu X (2012) Carbon nanodots as fluorescence probes for rapid, sensitive, and label-free detection of $\mathrm{Hg} 2+$ and biothiols in complex matrices. Chem Commun (Camb) 48(8):1147-1149, doi: 10.1039/ c2cc16791c

doi:10.1186/2193-1801-3-615

Cite this article as: Wright et al:: Carbon nanodots interference with lactate dehydrogenase assay in human monocyte THP-1 cells. SpringerPlus 2014 3:615.

\section{Submit your manuscript to a SpringerOpen ${ }^{\odot}$ journal and benefit from:}

- Convenient online submission

- Rigorous peer review

- Immediate publication on acceptance

- Open access: articles freely available online

- High visibility within the field

- Retaining the copyright to your article

Submit your next manuscript at $>$ springeropen.com 